\title{
Different time and space resources supply and demand matching degree taxis
}

\author{
Jianchun Liu \\ School of North China Electric Power University Baoding 071000, China. \\ 765999258@qq.com
}

Keywords: Analytic hierarchy,Entropy,SOM network.

\begin{abstract}
Taxi is one of the important means of transport residents travel, "difficult to take a taxi" is a social hot spot of people. Different time and space taxi resources matching degree is different, so we choose several reasonable indicators to analyze, respectively is the coordination of supply and demand coefficient, the elasticity of supply and demand, load factors, ownership mileage utilization and ten thousand people. This paper about how to make use of these five indexes for the matching of supply and demand, through the analysis of China's major cities taxi degree of the matching of supply and demand.
\end{abstract}

\section{Introduction}

According to the related data and definition, we can directly use formula to calculate the coordination coefficient of each year. Solving the degree of the elasticity of supply and demand, we first to demand and supply in the period from 2011 to 2011 years of data for fitting respectively, and get in the growth rate of each time node, and then calculate the elasticity of supply and demand. We in Beijing data from 2011-2014 ${ }^{[1]}{ }^{[2]}$, for example, first carries on the quadratic function fitting (as shown in figure 1), the fitting curve of the demand and supply, respectively

$$
y_{1}=-0.04 x^{2}+0.324 x+8.0325 \text { and } y_{2}=-0.0175 x^{2}+0.1505 x+6.6675
$$

Fitting degree reached $98.16 \%$ and $98.76 \%$ respectively, the fitting is very high, and the fitting curve can be used to calculate the elasticity of supply and demand of Beijing degree of 0.638 .

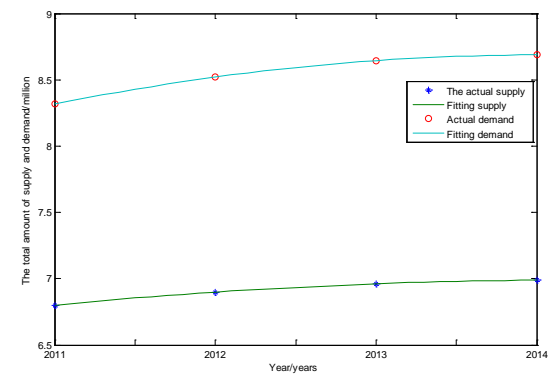

Figure 1 Fitting curve of the demand and supply

\section{Tthe appraisal model of the matching of supply and demand}

In the process, we identified the five indicators to analyze the reasonable degree of the matching of supply and demand. To comprehensive said the five indicators to analyze the degree of reasonable matching, we first define a matching coefficient of rationalization, then initial weight coefficient is obtained by hierarchy analysis model, using entropy method to modify it. According to the normalized index score matrix, combined with the weight proportion get the matching coefficient of rationalization.

Hierarchical analysis model to determine the weight of each indicator:

We through hierarchy analysis model to determine the first 5 indicators weights in the evaluation process, build a hierarchical analysis system: 


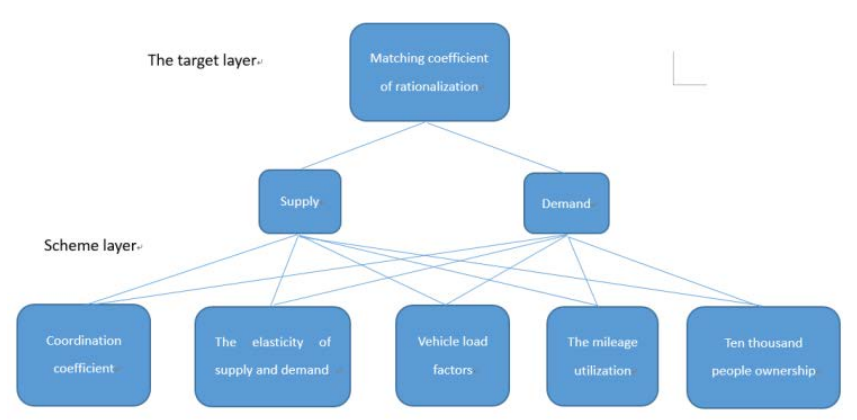

Figure 2 Graphic analytic hierarchy model

Analytic hierarchy process (ahp) contains both qualitative analysis and quantitative analysis also contains, is a kind of preference subjective evaluation method, we construct the paired comparison matrix:

Get the weight of each indicator:

$$
\left[\begin{array}{ccccc}
1 & \frac{3}{2} & \frac{5}{4} & 2 & \frac{6}{5} \\
\frac{2}{3} & 1 & \frac{5}{6} & \frac{4}{3} & \frac{3}{4} \\
\frac{4}{5} & \frac{6}{5} & 1 & \frac{3}{2} & 1 \\
\frac{1}{2} & \frac{3}{4} & \frac{2}{3} & 1 & \frac{4}{5} \\
\frac{5}{6} & \frac{4}{3} & 1 & \frac{5}{4} & 1
\end{array}\right]
$$

Table1 Analytic hierarchy process (ahp) gains weight

\begin{tabular}{clllll}
\hline Indicators & $\begin{array}{l}\text { Coordination } \\
\text { coefficient }\end{array}$ & $\begin{array}{l}\text { Degree of } \\
\text { elasticity }\end{array}$ & Utilised & $\begin{array}{l}\text { The mileage } \\
\text { utilization }\end{array}$ & $\begin{array}{l}\text { Ten thousand } \\
\text { people ownership }\end{array}$ \\
\hline Weight & 0.2642 & 0.1740 & 0.2102 & 0.1422 & 0.2095 \\
\hline
\end{tabular}

\section{Entropy method of correction:}

Analytic hierarchy process (ahp) method of determining weight of subjective factors, it is more to a certain extent, reflects the willingness of the selection of weight, has certain rationality and good interpretability. However, only using the analytic hierarchy process (ahp) will inevitably because people caused by the subjective cognitive weight distribution is not reasonable. In order to made a more objective to determine the weight of meaning, we select entropy value method to further calibration weights.

Entropy value method is the distance by judging the various indicators in level to determine the weight of each index, when the scale of the object is a parameter values is large, the entropy value is small, shows that the index to provide effective information is bigger, the weight should be bigger; Conversely, when the scale of the object of an index difference is small, the entropy value is bigger, show that the indicators provide the effective information is small, the weight should be less ${ }^{[2]}$.

According to the entropy value method calculated results for each target five indicators of weight coefficient, and the analytic hierarchy weighting according to 0.2:0.8 the proportion of correcting get five indicators of the final weight coefficient (see table 2).

Table2 Weight analysis table

\begin{tabular}{lllccl}
\hline Indicators & $\begin{array}{l}\text { Coordination } \\
\text { coefficient }\end{array}$ & $\begin{array}{l}\text { Degree of } \\
\text { elasticity }\end{array}$ & Utilised & $\begin{array}{l}\text { The mileage } \\
\text { utilization }\end{array}$ & $\begin{array}{l}\text { Ten thousand } \\
\text { people } \\
\text { ownership }\end{array}$ \\
\hline $\begin{array}{l}\text { Entropy } \\
\text { weight }\end{array}$ & 0.2952 & 0.1571 & 0.1794 & 0.1750 & 0.1753 \\
\hline $\begin{array}{l}\text { Fixed } \\
\text { weight }\end{array}$ & 0.2704 & 0.1742 & 0.2040 & 0.1488 & 0.2026 \\
\hline
\end{tabular}

Results for the five indicators of weighted according to the weight coefficient of rationalization is the matching of supply and demand quantity, representation is as follows:

$$
C=\omega_{1} H+\omega_{2} E+\omega_{3} F+\omega_{4} U+\omega_{5} \tilde{N}
$$




\section{Spatial analysis:}

\section{SOM neural network to the city}

Chinese cities are numerous, it is difficult to analyze all city taxi matching supply and demand status. As far as possible in order to simplify the calculation , we select the typical city to analyze. The first thing, we get 15 in geography, economic level, has a good representative of city traffic level, and then according to the city's GDP, CPI, these economic indicators and taxi total revenue, and the total bus traffic level indicators for classification of these cities, and then selected by analyzing the typical cities in each category. Because there is no ready-made classification standard for reference, So we choose no tutor system SOM neural network classification.

Through the analysis summary, points in the first category of Beijing and Shanghai are GDP and fiscal revenue, the total number of taxis and buses are at the highest level, also can reflect the economy of the two cities, the level of traffic in the front row, belong to the kind of city is developed city. Cities in the second category of economic level and the level of traffic slightly inferior to the city, belongs to the more developed cities; The other three cities compared with category and the category belongs to the city in general.

\section{Results and analysis:}

Beijing, chengdu, taiyuan three cities were analyzed, and the calculated by looking up and three cities in 2013, five analysis indicators summary table as follows:

Table 3 Each index summary

\begin{tabular}{llllll}
\hline City & $\begin{array}{l}\text { Coordination } \\
\text { coefficient }\end{array}$ & $\begin{array}{l}\text { Degree of } \\
\text { elasticity }\end{array}$ & Utilised & $\begin{array}{l}\text { The mileage } \\
\text { utilization }\end{array}$ & $\begin{array}{l}\text { Ten thousand } \\
\text { people } \\
\text { ownership }\end{array}$ \\
\hline Beijing & 0.6819 & 0.638 & 0.68 & 0.68 & 0.936 \\
\hline Chengdu & 0.5127 & 0.626 & 0.70 & 0.6788 & 0.653 \\
\hline Taiyuan & 0.478 & 0.38 & 0.62 & 0.50 & 0.958 \\
\hline
\end{tabular}

According to the hierarchical analysis model above, the three cities of normalized index into the matching rationalization of model can get these cities index in the following table:

Table 4Match the rationalization indexes

\begin{tabular}{llll}
\hline City & Beijing & Chengdu & Taiyuan \\
\hline $\begin{array}{l}\text { Matching coefficient of } \\
\text { rationalization }\end{array}$ & 0.716 & 0.618 & 0.590 \\
\hline
\end{tabular}

Through consulting relevant data and combining with the knowledge, we will match the rationalization index is divided into four categories: as the senior, as a senior, intermediate, junior. The analysis of the three city taxi resources matching degree, Beijing has the highest matching index of rationalization, but all belong to the higher, and chengdu taxi resources level needs to improve the matching of supply and demand, taiyuan match level is low, the taxi resources use is not very reasonable.

In order to validate the rationality of the model, we turn to the relevant information and news, although Beijing is the capital city, but with the increase of population, the increase of the number of the taxi is not very big, so the matching degree is not high. Chengdu and taiyuan taxi number has been a small number of problems, so the match reasonable index is lower, which to a certain extent, reflects the rationality of the model.

Time analysis:

Matching rational index to analyze the trend of change over time, we are here in a year, for the unit analysis of Beijing, chengdu, taiyuan three rationalization index matching city from 2012 to 2014, as shown in figure 3: 


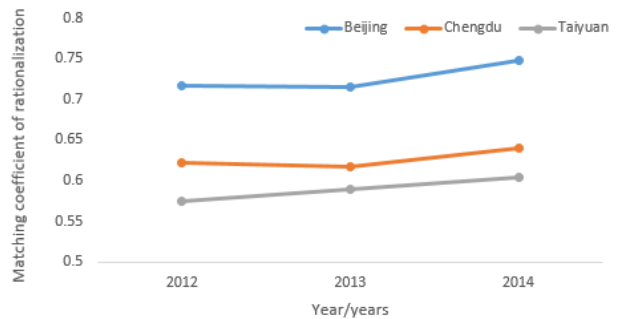

Figure 3 Match rationalization coefficient variation over time

\section{Analyzed by the figure 3:}

During 2012-2013, Beijing, chengdu, taiyuan match rationalization coefficient does not change significantly over time, a slight decline in Beijing, chengdu, taiyuan rose slightly.

\section{Summary:}

Through the interpretation of this article, we know some of the city's taxi resources matching degree, also know how to pass a number of indicators to analyze a city taxi resources matching degree, this control provides a solid theoretical basis for the government, and provides a taxi software company to upgrade with real data.

\section{Reference:}

[1]Beijing traffic development research center, 2013 Beijing traffic development annual report [J], 2014.

[2]Tianchao Lu: Entropy method and the analytic hierarchy process (ahp) application in determining weight [M], China mining university institute of computer science.

[3]The three major indicators of taxi supply and demand - the mileage utilization - vehicle load factors - ten thousand ownership [J], "transport manager world" 05, 2007.

[4]China statistical yearbook (2014) [M]. Beijing: China statistics press 